\title{
Small Bowel Endoscopic Bariatric Therapies
}

\author{
Eun Jeong Gong ${ }^{1}$ and Do Hoon Kim² \\ ${ }^{1}$ Department of Internal Medicine, Gangneung Asan Hospital, Gangneung, ${ }^{2}$ Department of Gastroenterology, University of Ulsan College of \\ Medicine, Asan Medical Center, Seoul, Korea
}

Endoscopic bariatric therapies that emulate some of the principles of bariatric surgery have been developed as a less invasive option for the treatment of obesity and related comorbidities. Small bowel endoscopic bariatric therapies include bypass sleeves, incisionless anastomosis systems, and duodenal mucosal resurfacing. Clinical experience with small bowel devices suggests that endoscopic bariatric procedures can be safely implemented and that these devices are effective for both weight loss and metabolic improvement. Although the mechanisms behind these effects should be further elucidated, endoscopic bariatric therapies may be more effective and safer adjunctive interventions than lifestyle modifications and pharmacological regimens for patients with obesity or obesity-related comorbidities. Clin Endosc 2018;51:425-429

Key Words: Bariatrics; Endoscopy; Obesity; Intestine, small; Weight loss

\section{INTRODUCTION}

Obesity continues to be a significant problem worldwide and is associated with comorbidities such as diabetes, hypertension, dyslipidemia, obstructive sleep apnea, and non-alcoholic fatty liver disease. ${ }^{1}$ Treatment options for obesity include lifestyle interventions, pharmacotherapy, and bariatric surgery. Among these, the most successful and durable strategy is bariatric surgery. Experimental evidence demonstrates that bypass surgery may affect glucose metabolism, highlighting the significance of small bowel manipulation in bariatric and metabolic therapies. ${ }^{2}$ Roux-en-Y gastric bypass (RYGB) surgery has been demonstrated to affect weight loss and improve glucose intolerance in patients with type 2 diabetes mellitus (T2DM).

Received: September 2, 2018 Revised: September 16, 2018

Accepted: September 19, 2018

Correspondence: Do Hoon Kim

Department of Gastroenterology, University of Ulsan College of Medicine, Asan Medical Center, 88 Olympic-ro 43-gil, Songpa-gu, Seoul 05505, Korea

Tel: +82-2-3010-3193, Fax: +82-2-476-0824, E-mail: dohoon.md@gmail.com ORCID: https://orcid.org/0000-0002-4250-4683

cc This is an Open Access article distributed under the terms of the Creative Commons Attribution Non-Commercial License (http://creativecommons.org/ licenses/by-nc/3.0) which permits unrestricted non-commercial use, distribution, and reproduction in any medium, provided the original work is properly cited.
Endoscopic bariatric therapies (EBTs) enable patients to lose weight by targeting the stomach or small bowel, similarly to bariatric surgery but with less invasiveness and better safety. ${ }^{5,6}$ EBTs could be an alternative treatment for patients with mild to moderate obesity who have not been able to lose weight with nonsurgical therapy and who do not qualify for bariatric surgery. This review focuses on small bowel EBTs, including endoluminal sleeves, the incisionless anastomosis system, and resurfacing of the duodenal mucosa.

\section{ENDOLUMINAL SLEEVES}

Two hypotheses have been proposed to explain the effect of endoluminal sleeves on T2DM. The "foregut hypothesis" proposes that the exclusion of the "foregut", duodenum and proximal jejunum, and the accelerated delivery of poorly digested nutrients to the "hindgut" possibly prevent secretion of a putative signal that promotes insulin resistance and $\mathrm{T}_{2} \mathrm{DM}^{7-10}$ The "hindgut hypothesis" assumes that diabetes control results from the accelerated delivery of nutrients to the distal intestine, enhancing a physiological signal that improves glucose metabolism and weight loss by accentuation of an "ileal brake."1-14 The weight management of the ileal brake 
is based on several findings. First, activation of the ileal brake causes a reduction in food intake and an increase in satiety. Second, the increased exposure of the ileum to nutrients by endoscopic or surgical procedures causes weight loss and improves glucose control. Third, the appetite-lowering effect of chronic ileal brake activation seems to be sustained over time. $^{15}$

\section{Duodenal-jejunal bypass liner}

EndoBarrier (GI Dynamics, Lexington, MA, USA; Fig. 1A) is a $60-\mathrm{cm}$-long, highly flexible, Teflon fluoropolymer duodenal-jejunal bypass liner (DJBL). The device is deployed under endoscopic and fluoroscopic guidance with a self-expanding nitinol anchor in the duodenal bulb, and the liner extends into the proximal jejunum, allowing nutrients to pass directly from the stomach into the jejunum. Pancreatic enzymes and bile flow down between the liner and the intestinal wall, mixing with nutrients at the jejunum. This device is placed for 3-12 months and then removed endoscopically.

Both the exclusion of the duodenal-jejunal nutrient flow and rapid delivery of undigested nutrients and bile acid to the distal small intestine are thought to play roles in the weight loss and improvement of glucose metabolism. ${ }^{2,16}$ Similar to the foregut hypothesis, exclusion of the proximal small intestine from coming into contact with nutrients potentially downregulates the production of anti-incretins, which leads to the mitigation of insulin resistance. ${ }^{17}$ Furthermore, early delivery of bile and nutrients to the distal small intestine stimulates $\mathrm{L}$ cells in the terminal ileum and proximal colon to secrete gut hormones such as glucagon-like peptide 1 (GLP-1) and peptide YY (PYY), which are implicated in the incretin effect and satiety. ${ }^{18,19}$
(A)

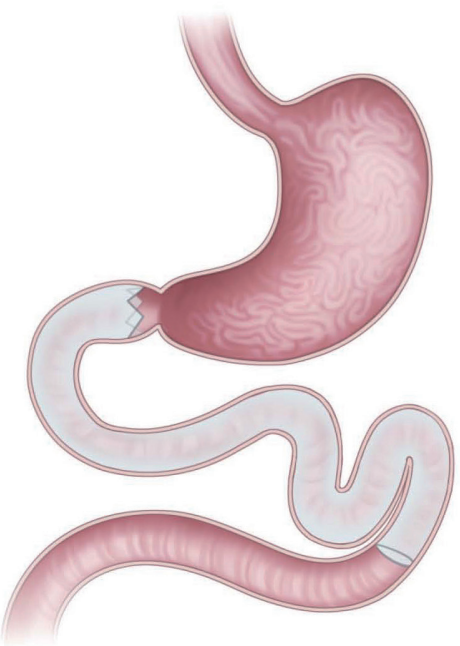

(C)

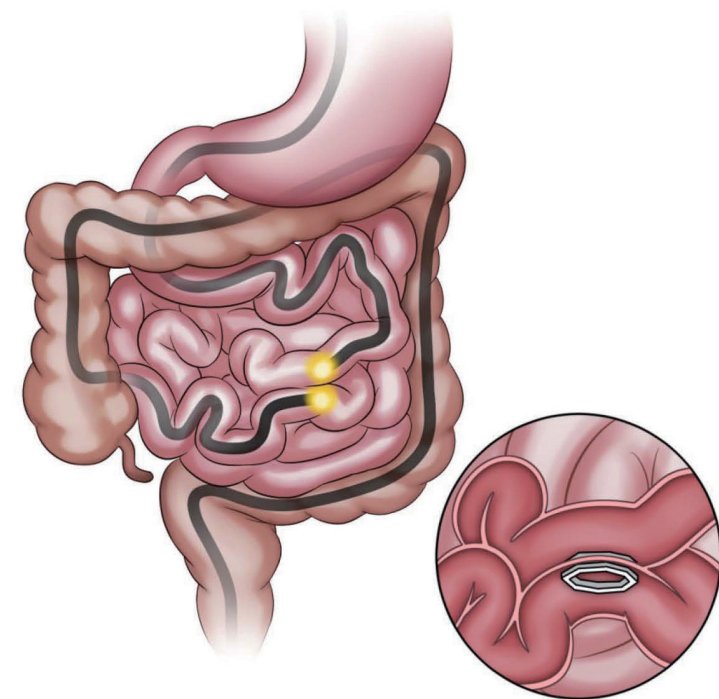

(B)

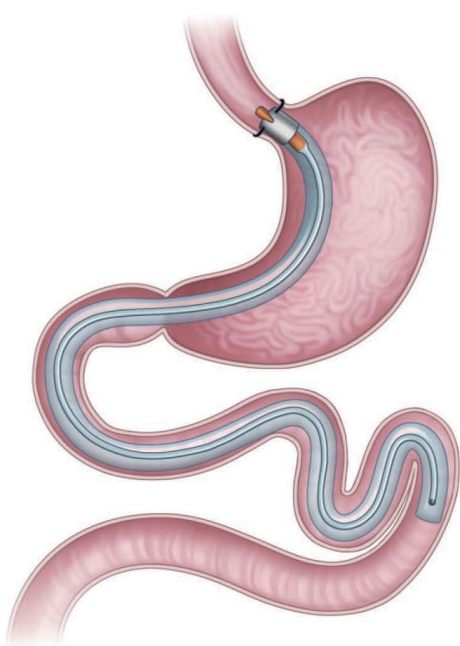

(D)

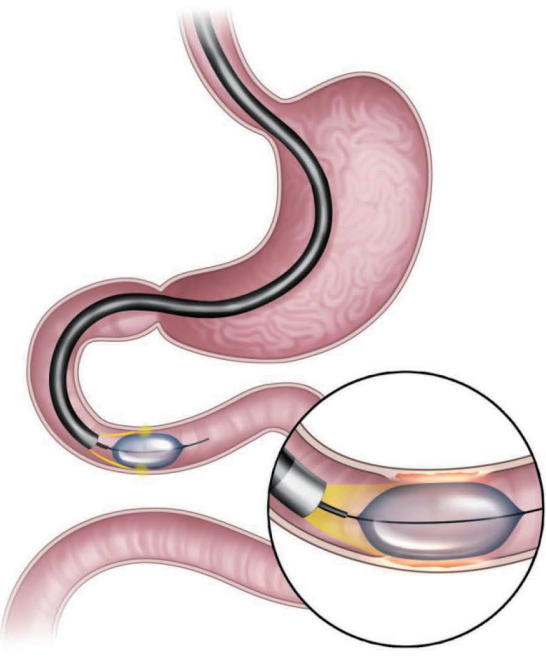

Fig. 1. Small bowel endoscopic bariatric therapies: (A) Duodenaljejunal bypass liner, (B) gastroduodenojejunal bypass sleeve, (C) incisionless anastomosis system, and (D) duodenal mucosal resurfacing. 
The effectiveness and safety of DJBL have been assessed over several studies, which have demonstrated significant weight loss and improvements in several metabolic parameters. To date, five published randomized controlled trials have compared DJBL with a placebo or control arm (Table 1). ${ }^{20-24}$ A previous meta-analysis reported that patients who undergo DJBL interventions achieve an excess weight loss (EWL) of 35.3\% (95\% confidence interval [CI], 24.6\%-46.1\%) at 12 months. ${ }^{25}$ Another meta-analysis, which include four randomized controlled studies, showed that DJBL resulted in $12.6 \%$ EWL (95\% CI, 9.0\%-16.2\%) as compared with diet modification in patients with obesity and T2DM. ${ }^{26}$ In addition to the short-term clinical outcomes, a few studies have shown that EWL may remain detectable 6 to 12 months after device removal. ${ }^{24}$ However, over the long term, patients may gain weight, with reportedly $74 \%$ of patients experiencing weight regain within the first 6 months after device removal. ${ }^{16,27,28}$

The device also appears to have an impact on glycemic control, as demonstrated by reductions in glycated hemoglobin
(HbAlc) levels. A recent meta-analysis assessed the effect of DJBL on glycemic control in patients with obesity and T2DM and showed that DJBL was associated with an EWL of 36.9\% (95\% CI, 29.2\%-44.6\%) and a decrease in HbAlc level of 1.3\% (95\% CI, $1.0 \%-1.6 \%)$ relative to control subjects. ${ }^{19}$ In addition, DJBL was associated with increases in GLP-1 and PYY levels, and a decrease in glucose-dependent insulinotropic peptide level, which suggests mechanisms similar to RYGB.

Adverse events reported with the DJBL include abdominal pain, nausea, and vomiting. Almost all patients with DJBL have been reported to experience mild-to-moderate adverse events, which can be improved with conservative management. ${ }^{26}$ Associated serious adverse events include sleeve migration (4.9\%), gastrointestinal bleeding (3.9\%), sleeve obstruction $(3.4 \%)$, liver abscess $(0.1 \%)$, cholangitis $(0.1 \%)$, acute cholecystitis (0.1\%), and esophageal perforation $(0.1 \%) .{ }^{25}$ Early device removal has been required in up to $38 \%$ of patients, due to bleeding, migration, obstruction, or abdominal pain. ${ }^{20-}$ ${ }^{24}$ No case of procedure-related mortality has been reported.

Table 1. Randomized Controlled Studies That Assessed Clinical Outcomes of Duodenaljejunal Bypass Liner

\begin{tabular}{|c|c|c|c|c|c|c|c|}
\hline $\begin{array}{c}\text { Study } \\
\text { Author(year) }\end{array}$ & Number ${ }^{a)}$ & Age, yr & BMI, $\mathrm{kg} / \mathrm{m}^{2}$ & $\begin{array}{l}\text { Duration, } \\
\text { weeks }\end{array}$ & $\begin{array}{c}\text { HbAlc, } \% \\
\text { preoperative }\end{array}$ & $\begin{array}{c}\text { HbAlc, } \% \\
\text { postoperative }\end{array}$ & $\%$ EWL \\
\hline $\begin{array}{l}\text { Rodriguez et al. } \\
(2009)^{20}\end{array}$ & 18 & & & 24 & & & \\
\hline DJBL & $12(12)$ & $45 \pm 7$ & $38.9 \pm 5.9$ & & $9.2 \pm 1.7$ & $-2.4 \pm 0.7^{\mathrm{b})}$ & \\
\hline Sham & $6(6)$ & $51 \pm 13$ & $39.0 \pm 7.2$ & & $9.0 \pm 2.0$ & $-0.8 \pm 0.4^{\mathrm{b})}$ & \\
\hline Tarnoff et al. $(2009)^{21}$ & 39 & & & 12 & & & \\
\hline DJBL & $25(3)$ & $38.0 \pm 10.1$ & $42.0 \pm 5.1$ & & 6.6 (range, 5.5-7.8) & 6.0 (range, $5.8-7.1)$ & $22.1 \pm 8^{*}$ \\
\hline Control & $14(1)$ & $43.0 \pm 10.6$ & $40.0 \pm 3.5$ & & 12.6 & 7.8 & $5.3 \pm 6.6^{*}$ \\
\hline Gersin et al. $(2010)^{22}$ & 47 & & & 12 & & & \\
\hline DJBL & $21(14)$ & $45 \pm 7$ & $46 \pm 5$ & & $7.7 \pm 2.5$ & $7.2 \pm 2.1$ & $11.9 \pm 1.4^{*}$ \\
\hline Sham & $26(12)$ & $43 \pm 10$ & $46 \pm 6$ & & $7.6 \pm 1.3$ & $6.8 \pm 0.2$ & $2.7 \pm 2.0^{*}$ \\
\hline $\begin{array}{l}\text { Schouten et al. } \\
(2010)^{23}\end{array}$ & 37 & & & 12 & & & \\
\hline DJBL & $26(8)$ & $40.9(20-59)$ & $48.9(39-60)$ & & $8.8 \pm 1.7$ & $7.7 \pm 1.8$ & $19.0 \pm 10.9^{* *}$ \\
\hline Control & $11(2)$ & $41.2(19-57)$ & $49.2(37-60)$ & & $7.3 \pm 0.1$ & $6.9 \pm 0.6$ & $6.9 \pm 6.1^{\star *}$ \\
\hline $\begin{array}{l}\text { Koehestanie et al. } \\
(2014)^{24}\end{array}$ & 73 & & & 24 & & & \\
\hline DJBL & $34(34)$ & $\begin{array}{c}49.5(\mathrm{IQR} \\
42-58)\end{array}$ & $\begin{array}{r}34.6(\mathrm{IQR} \\
32.4-38.1)\end{array}$ & & 8.3 (IQR 7.7-9.0) & $\begin{array}{c}7.0(\mathrm{IQR} \\
6.4-7.5)^{\star *}\end{array}$ & $\begin{array}{c}32.0(\mathrm{IQR} \\
22.0-46.7)^{\star *}\end{array}$ \\
\hline Control & $39(39)$ & $\begin{array}{c}49.0(\mathrm{IQR} \\
44-55)\end{array}$ & $\begin{array}{l}36.8(\mathrm{IQR} \\
32.6-42.0)\end{array}$ & & 8.3 (IQR 7.7-8.9) & $\begin{array}{c}7.9(\mathrm{IQR} \\
6.6-8.3)^{\star *}\end{array}$ & $\begin{array}{c}16.4(\mathrm{IQR} \\
4.1-34.6)^{\star *}\end{array}$ \\
\hline
\end{tabular}

Data are presented as numbers, means \pm standard deviation, or median (range).

BMI, body mass index; HbA1c, glycated hemoglobin; EWL, excess weight loss; DJBL, duodenal-jejunal bypass liner; IQR, interquartile range.

${ }^{a)}$ Parenthesis: number of patients with diabetes mellitus.

${ }^{b)}$ Change in HbAlc level.

${ }^{*} p<0.001,{ }^{* *} p<0.05$. 
Although DJBL is a promising treatment option for patients with obesity and T2DM hitherto and showed acceptable safety profiles, the risks and benefits of the procedure should be weighed carefully during clinical practice. ${ }^{29,30}$

\section{Gastroduodenojejunal bypass sleeve}

The ValenTx gastroduodenojejunal bypass sleeve (ValenTx Endoluminal Bypass, Hopkins, MN, USA; Fig. 1B) is a 120 -cm-long fluoropolymer sleeve designed to be anchored to the gastroesophageal junction. The implantation procedure is both endoscopic and laparoscopic, with laparoscopy allowing for external visualization to ensure transmural anchor placement at the gastroesophageal junction. The sleeve extends from the stomach to the jejunum, allowing nutrients to bypass the stomach, duodenum, and proximal jejunum. The device can be removed endoscopically through endoscopic ligation of the anchoring sutures.

Early experiences with the device in morbidly obese patients have shown substantial weight loss and metabolic improvements. ${ }^{31,32}$ In one study, the device was successfully delivered in 22 (92\%) of 24 patients, with five patients (23\%) requiring early removal of the device because of odynophagia. ${ }^{31}$ The device resulted in $39.7 \%$ EWL (range, 27\%-64\%) at 3 months, and 7 patients with T2DM had normal blood glucose levels throughout the trial. In another study, initial device implantation was successful in all patients, and only two patients $(17 \%)$ required early removal due to dysphagia or odynophagia. ${ }^{32}$ In six of 10 patients whose sleeves were fully attached throughout the study period, the mean EWL was $54 \%$ at 12 months. In the remaining four patients, partial cuff detachment was observed at follow-up endoscopy, and the mean EWL was lower than that of the patients with full attachment. Four patients with T2DM showed improvement in HbA1c and fasting blood glucose levels. No other significant adverse events were encountered during follow-up.

\section{INCISIONLESS ANASTOMOSIS SYSTEM}

Dual-path enteral bypass is achieved endoscopically by creating a jejuno-ileal bypass using self-assembling magnets (Incisionless Magnetic Anastomosis System; GI Windows, Boston, MA, USA; Fig. 1C). ${ }^{33}$ This system requires simultaneous enteroscopy and colonoscopy, whereby the magnets are deployed from the working channel of each endoscope. Once deployed and coupled, the octagonally shaped magnets create a large-bore compression anastomosis that allows partially digested contents to pass rapidly to the distal ileum. The coupled magnets pass spontaneously through the stool; therefore, the dual-path enteral bypass system does not require further intervention for device removal. A preliminary study of 10 morbidly obese patients with a mean body mass index of $41 \mathrm{~kg} / \mathrm{m}^{2}$ demonstrated the technical feasibility and durable patency of dual-pass enteral bypass. ${ }^{34}$ This bypass strategy has resulted in $10.6 \%$ total weight loss and $28.3 \%$ EWL at 6 months. In addition, this system has been associated with significant reductions in $\mathrm{HbAlc}$ and fasting blood glucose levels after 6 months in patients with prediabetes or T2DM.

\section{DUODENAL MUCOSAL RESURFACING}

Duodenal mucosal resurfacing (DMR; Fractyl, Lexington, MA, USA; Fig. 1D) is an endoscopic procedure that achieves hydrothermal ablation of the duodenal mucosa. The procedure consists of duodenal sizing, saline expansion of the submucosal space, and hydrothermal ablation of superficial layers to allow a restoration of a normal mucosal interface that corrects abnormal metabolic signaling. A polyethylene terephthalate balloon catheter is introduced into the duodenum, and circumferential mucosal lifting is performed along the length of the postpapillary duodenum. After removal of the initial catheter, a $2.0-\mathrm{cm}$-long balloon on the catheter is introduced and inflated with heated water for circumferential ablation of the duodenal mucosa. Under direct endoscopic visualization, circumferential thermal ablations of about 10 seconds each are applied at temperatures of approximately $90^{\circ} \mathrm{C}$ to obtain the desired length of mucosal ablation.

The first human study of DMR with varying lengths showed favorable short-term outcomes with acceptable tolerability. ${ }^{35}$ Both long- $(\geq 9 \mathrm{~cm})$ and short-segment DMR $(<6$ $\mathrm{cm})$ resulted in a significant improvement in the glycemic indexes of patients with T2DM over 6 months of follow-up. The HbAlc level decreased by a mean of $1.2 \% \pm 0.3 \%$ in the full cohort, and this effect was greater in long-segment DMR than in short-segment DMR. The most common adverse event was transient abdominal pain after the procedure. Duodenal stenosis occurred in three patients 2-6 weeks after the procedure and was treated successfully with endoscopic balloon dilation. A modest effect on body weight was observed during the 6-month period, which suggests that the metabolic effect was unlikely to be related to the alterations in body weight.

\section{CONCLUSIONS}

Small bowel EBTs have produced promising results in weight loss and metabolic parameters, with reasonable safety profiles. EBTs are more effective than lifestyle modification and are less invasive and thus safer than bariatric surgery. 
However, weight loss produced by EBTs is less durable than that achieved by bariatric surgery, and maintenance strategies are necessary. A multidisciplinary approach to EBT use in conjunction with lifestyle interventions and medications may be beneficial to optimize long-term treatment outcomes. Elucidating the mechanisms underlying the effects of small bowel EBTs may provide more information, including clues to guide device and procedural improvements.

\section{Conflicts of Interest}

The authors have no financial conflicts of interest.

\section{REFERENCES}

1. Adams KF, Schatzkin A, Harris TB, et al. Overweight, obesity, and mortality in a large prospective cohort of persons 50 to 71 years old. N Engl J Med 2006;355:763-778.

2. Rubino F, Forgione A, Cummings DE, et al. The mechanism of diabetes control after gastrointestinal bypass surgery reveals a role of the proximal small intestine in the pathophysiology of type 2 diabetes. Ann Surg 2006;244:741-749.

3. Schauer PR, Bhatt DL, Kirwan JP, et al. Bariatric surgery versus intensive medical therapy for diabetes - 5-year outcomes. N Engl J Med 2017;376:641-651.

4. Mingrone G, Panunzi S, De Gaetano A, et al. Bariatric-metabolic surgery versus conventional medical treatment in obese patients with type 2 diabetes: 5 year follow-up of an open-label, single-centre, randomised controlled trial. Lancet 2015;386:964-973.

5. Sullivan S, Edmundowicz SA, Thompson CC. Endoscopic bariatric and metabolic therapies: new and emerging technologies. Gastroenterology 2017;152:1791-1801.

6. Jirapinyo P, Thompson CC. Endoscopic bariatric and metabolic therapies: surgical analogues and mechanisms of action. Clin Gastroenterol Hepatol 2017;15:619-630.

7. Machytka E, Bužga M, Zonca P, et al. Partial jejunal diversion using an incisionless magnetic anastomosis system: 1-year interim results in patients with obesity and diabetes. Gastrointest Endosc 2017;86:904-912.

8. Rubino F, Gagner M. Potential of surgery for curing type 2 diabetes mellitus. Ann Surg 2002;236:554-559.

9. Pories WJ, Albrecht RJ. Etiology of type II diabetes mellitus: role of the foregut. World J Surg 2001;25:527-531.

10. Rubino F, Gagner M, Gentileschi P, et al. The early effect of the Rouxen-Y gastric bypass on hormones involved in body weight regulation and glucose metabolism. Ann Surg 2004;240:236-242.

11. Cummings DE, Overduin J, Foster-Schubert KE. Gastric bypass for obesity: mechanisms of weight loss and diabetes resolution. J Clin Endocrinol Metab 2004;89:2608-2615.

12. Mason EE. The mechanisms of surgical treatment of type 2 diabetes. Obes Surg 2005;15:459-461.

13. Patriti A, Facchiano E, Sanna A, Gullà N, Donini A. The enteroinsular axis and the recovery from type 2 diabetes after bariatric surgery. Obes Surg 2004;14:840-848.

14. Mason EE. Ileal [correction of ilial] transposition and enteroglucagon/ GLP-1 in obesity (and diabetic?) surgery. Obes Surg 1999;9:223-228.

15. Maljaars PW, Peters HP, Mela DJ, Masclee AA. Ileal brake: a sensible food target for appetite control. A review. Physiol Behav 2008;95:271281.

16. Cohen R, le Roux CW, Papamargaritis D, et al. Role of proximal gut exclusion from food on glucose homeostasis in patients with type 2 dia- betes. Diabet Med 2013;30:1482-1486.

17. Dixon JB, le Roux CW, Rubino F, Zimmet P. Bariatric surgery for type 2 diabetes. Lancet 2012;379:2300-2311.

18. Meek CL, Lewis HB, Reimann F, Gribble FM, Park AJ. The effect of bariatric surgery on gastrointestinal and pancreatic peptide hormones. Peptides 2016;77:28-37.

19. Jirapinyo P, Haas AV, Thompson CC. Effect of the duodenal-jejunal bypass liner on glycemic control in patients with type 2 diabetes with obesity: a meta-analysis with secondary analysis on weight loss and hormonal changes. Diabetes Care 2018;41:1106-1115.

20. Rodriguez L, Reyes E, Fagalde P, et al. Pilot clinical study of an endoscopic, removable duodenal-jejunal bypass liner for the treatment of type 2 diabetes. Diabetes Technol Ther 2009;11:725-732.

21. Tarnoff M, Rodriguez L, Escalona A, et al. Open label, prospective, randomized controlled trial of an endoscopic duodenal-jejunal bypass sleeve versus low calorie diet for pre-operative weight loss in bariatric surgery. Surg Endosc 2009;23:650-656.

22. Gersin KS, Rothstein RI, Rosenthal RJ, et al. Open-label, sham-controlled trial of an endoscopic duodenojejunal bypass liner for preoperative weight loss in bariatric surgery candidates. Gastrointest Endosc 2010;71:976-982.

23. Schouten R, Rijs CS, Bouvy ND, et al. A multicenter, randomized efficacy study of the EndoBarrier gastrointestinal liner for presurgical weight loss prior to bariatric surgery. Ann Surg 2010;251:236-243.

24. Koehestanie P, de Jonge C, Berends FJ, Janssen IM, Bouvy ND, Greve JW. The effect of the endoscopic duodenal-jejunal bypass liner on obesity and type 2 diabetes mellitus, a multicenter randomized controlled trial. Ann Surg 2014;260:984-992.

25. ASGE Bariatric Endoscopy Task Force and ASGE Technology Committee, Abu Dayyeh BK, Kumar N, et al. ASGE bariatric endoscopy task force systematic review and meta-analysis assessing the ASGE PIVI thresholds for adopting endoscopic bariatric therapies. Gastrointest Endosc 2015;82:425-438.e5.

26. Rohde U, Hedbäck N, Gluud LL, Vilsbøll T, Knop FK. Effect of the EndoBarrier gastrointestinal liner on obesity and type 2 diabetes: a systematic review and meta-analysis. Diabetes Obes Metab 2016;18:300-305.

27. Betzel B, Koehestanie P, Homan J, et al. Changes in glycemic control and body weight after explantation of the duodenal-jejunal bypass liner. Gastrointest Endosc 2017;85:409-415.

28. Forner PM, Ramacciotti T, Farey JE, Lord RV. Safety and effectiveness of an endoscopically placed duodenal-jejunal bypass device (EndoBarrier): outcomes in 114 patients. Obes Surg 2017;27:3306-3313.

29. Betzel B, Koehestanie P, Aarts EO, et al. Safety experience with the duodenal-jejunal bypass liner: an endoscopic treatment for diabetes and obesity. Gastrointest Endosc 2015;82:845-852.

30. Quezada N, Muñoz R, Morelli C, et al. Safety and efficacy of the endoscopic duodenal-jejunal bypass liner prototype in severe or morbidly obese subjects implanted for up to 3 years. Surg Endosc 2018;32:260267.

31. Sandler BJ, Rumbaut R, Swain CP, et al. Human experience with an endoluminal, endoscopic, gastrojejunal bypass sleeve. Surg Endosc 2011;25:3028-3033.

32. Sandler BJ, Rumbaut R, Swain CP, et al. One-year human experience with a novel endoluminal, endoscopic gastric bypass sleeve for morbid obesity. Surg Endosc 2015;29:3298-3303.

33. Ryou M, Aihara H, Thompson CC. Minimally invasive entero-enteral dual-path bypass using self-assembling magnets. Surg Endosc 2016;30:4533-4538.

34. Machytka E, Buzga M, Ryou M, Lautz DB, Thompson CC. Endoscopic dual-path enteral anastomosis using self-assembling magnets: first-inhuman clinical feasibility. Gastroenterology 2016;150(4 Suppl 1):S232.

35. Rajagopalan H, Cherrington AD, Thompson CC, et al. Endoscopic duodenal mucosal resurfacing for the treatment of type 2 diabetes: 6-month interim analysis from the first-in-human proof-of-concept study. Diabetes Care 2016;39:2254-2261. 